\title{
Minimally Invasive Surgery for Inflammatory Bowel Disease
}

\author{
Jennifer Holder-Murray, MD, ${ }^{*}$ Priscilla Marsicovetere, $P A-C, J D,{ }^{+}$and Stefan $D$. Holubar, MD, $M S^{\dagger}$
}

\begin{abstract}
Surgical management of inflammatory bowel disease is a challenging endeavor given infectious and inflammatory complications, such as fistula, and abscess, complex often postoperative anatomy, including adhesive disease from previous open operations. Patients with Crohn's disease and ulcerative colitis also bring to the table the burden of their chronic illness with anemia, malnutrition, and immunosuppression, all common and contributing independently as risk factors for increased surgical morbidity in this high-risk population. However, to reduce the physical trauma of surgery, technologic advances and worldwide experience with minimally invasive surgery have allowed laparoscopic management of patients to become standard of care, with significant short- and long-term patient benefits compared with the open approach. In this review, we will describe the current stateof the-art for minimally invasive surgery for inflammatory bowel disease and the caveats inherent with this practice in this complex patient population. Also, we will review the applicability of current and future trends in minimally invasive surgical technique, such as laparoscopic "incisionless," singleincision laparoscopic surgery (SILS), robotic-assisted, and other techniques for the patient with inflammatory bowel disease. There can be no doubt that minimally invasive surgery has been proven to decrease the short- and long-term burden of surgery of these chronic illnesses and represents highvalue care for both patient and society.
\end{abstract}

(Inflamm Bowel Dis 2015;21:1443-1458)

S ince its introduction in the late 20th century, minimally invasive surgery (MIS) has evolved from simple elective laparoscopic cholecystectomy using large $12-\mathrm{mm}$ ports and a $10-\mathrm{mm}$ standard resolution camera, to complex 5-mm 3D-HD laparoscopy encompassing a variety of technologies that have allowed expansion of these techniques to even complex intra-abdominal and retroperitoneal pathology. Increasingly, these are applied to complex patients with difficult and advanced inflammatory bowel disease (IBD), such as fistulizing Crohn's disease (CD) or chronic ulcerative colitis (CUC) refractory to maximal medical therapy of corticosteroids and anti-TNF antibody therapy (Figs. 1 and 2). Although many surgeons have become comfortable with laparoscopic surgery for benign and malignant abdominal disease, such as colon cancer and sigmoid diverticulitis, the application of MIS to patients with complex IBD or rectal cancer, has been more slowly adopted. This is probably due to real and/or perceived technical difficulty in IBD, i.e., the frequent presence of chronically thickened/inflamed mesentery, friable tissues, abscesses, phlegmonous inflammatory masses, strictures, enteric fistula, chronically dilated loops of bowel, and multifocal abdominopelvic continuous or discontinuous involved segments of bowel. Patients

Received for publication October 1, 2014; Accepted November 18, 2014.

From the *Department of Surgery, Division of Colon and Rectal Surgery, University of Pittsburgh Medical Center, Pittsburgh, Pennsylvania; and ${ }^{\dagger}$ Division of Colon and Rectal Surgery, Dartmouth-Hitchcock Medical Center, Lebanon, New Hampshire.

The authors have no conflicts of interest to disclose.

Reprints: Stefan D. Holubar, MD, MS, Division of Colon and Rectal Surgery, Dartmouth-Hitchcock Medical Center, 1 Medical Center Drive, Lebanon, NH 03756 (e-mail: stefan.holubar@dartmouth.edu).

Copyright (C) 2015 Crohn's \& Colitis Foundation of America, Inc.

DOI 10.1097/MIB.0000000000000316

Published online 9 February 2015. with IBD also often have complex reoperative anatomy with multiple anastomoses, stomas, parastomal hernias, and adhesions from previous open operations. These patients have sequelae of their chronic illness: anemia, malnutrition, and immunosuppression, all contributing incrementally to risk of adverse postoperative outcomes. Given these issues, advanced IBD was not a disease for which early adoption of laparoscopic techniques was widespread.

Adoption of laparoscopic proctectomy for rectal cancer has also not been widespread. Oncologic principles are directly relevant to patients with IBD as approximately $12 \%$ of patients with CUC require surgery for neoplasia, and although MIS for colon cancer is present used in approximately $60 \%$ of cases nationwide, there have been concerns over the ability to perform total mesorectal excision and obtain a clear circumferential radial margin in rectal cancer, which is only used in approximately $30 \%$ of cases nationwide. ${ }^{1}$ To date, these fears have not been born out in randomized studies of colorectal cancer, such as the COST and COLOR trials. ${ }^{1-5}$

Thus, by the early 21 st century, numerous studies have demonstrated that minimally invasive colectomy and proctectomy for malignancy have improved short-term outcomes with comparable long-term outcomes and safety over traditional open surgery. ${ }^{6-14}$ MIS approaches are now the preferred approach for most colon and rectal diseases and are gaining traction in IBD. Small incisions with less pain and improved cosmesis (Fig. 3) a not unimportant factor in this often young-adult and pediatric population, and other benefits, such as more rapid return to full functional status like work and school-make the MIS approach to surgery appealing to the surgeon and patient alike. Furthermore, many patients with IBD are known a priori to require subsequent operative intervention for restoration of intestinal continuity or future resection, thus adhesion prevention with 


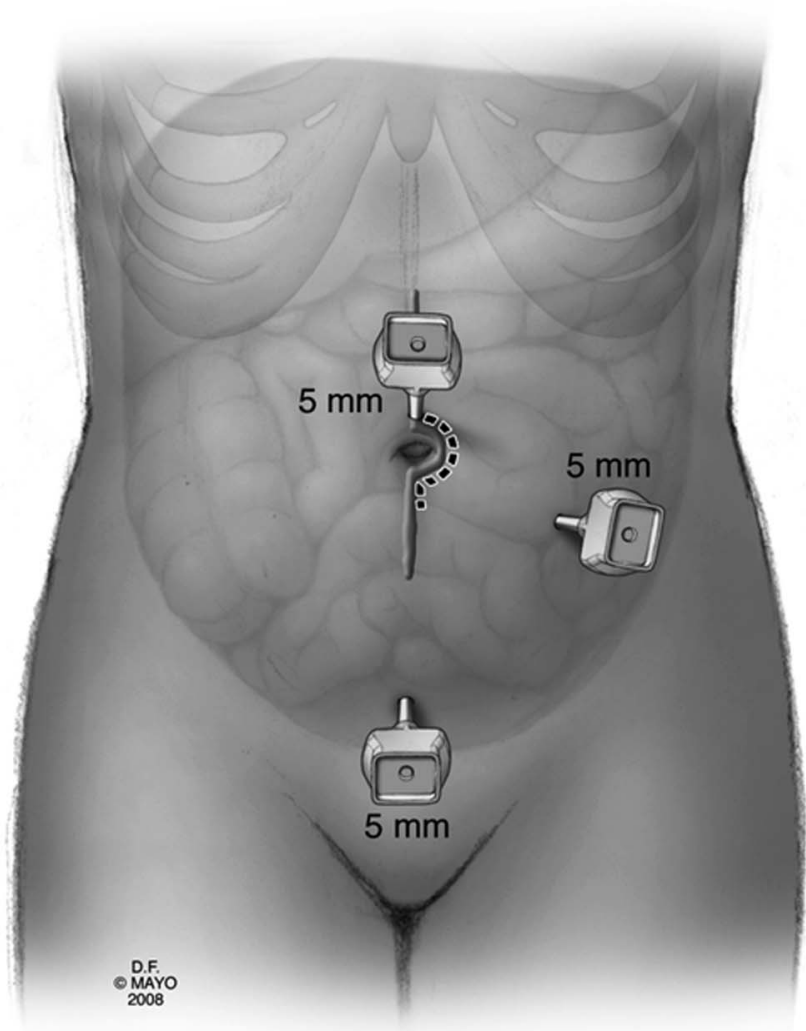

E1306131-003-0

FIGURE 1. MIS approach to laparoscopic ileocolic resection. Reprinted with permission from Holubar SD, Dozois EJ, Privitera A, Cima RR, et al. Laparoscopic surgery for recurrent ileocolic Crohn's disease. Inflamm Bowel Dis. 2010;16:1382-1386. Copyright (C) 2010 Crohn's \& Colitis Foundation of America, Inc. laparoscopy (not open surgery) and antiadhesion barrier products should be considered part of best practice for these patients to reduce the risk of adhesive small bowel obstruction. Clearly, the abdomen is likely to be far less hostile after a previous laparoscopic procedure than after a long midline laparotomy (Figs. 3 and 4).

In this review, we will summarize the current data on MIS in $\mathrm{CD}$ and then CUC, examining indications and contraindications to a minimally invasive approach in IBD (Table 1). The feasibility of MIS for IBD has been demonstrated in multiple small studies. Beyond IBD, the benefits of MIS surgery on patient outcomes have been proven in colectomy and proctectomy for both benign and malignant disease. Laparoscopic approaches have therefore increased in prevalence in the population of patients with IBD. However, complex and reoperative cases are still often approached in an open fashion despite ample evidence that these procedures can be performed both successfully and with significant short- and long-term benefits to the patient when done laparoscopically. ${ }^{15-17}$ Although not every patient with IBD is appropriate for MIS, complicated disease and multiple previous abdominal operations have been touted as the major relative contraindications to an MIS approach. ${ }^{18}$ However, it is worth considering whether the additional advances in technology and the ever-increasing technical expertise of the surgeons will allow for improved rates of laparoscopic resections in the more challenging cases. In 2008 , Edden et $\mathrm{al}^{16}$ published their series of patients from 1992 to 2005, demonstrating that redo surgeries and patients with complex disease often were not completed laparoscopically in the earlier years of the study. Moving on to present day, however, MIS is being used in ever-increasing complex CD cases, from recurrent surgery to fistulizing disease to intra-abdominal abscesses. ${ }^{16,19,20}$ As was found by Tan et al, the
A

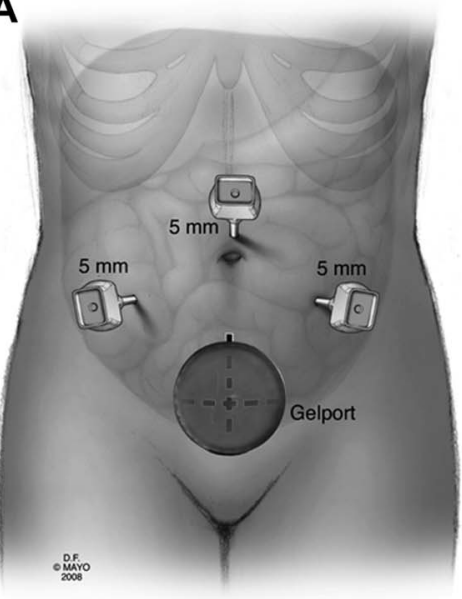

B

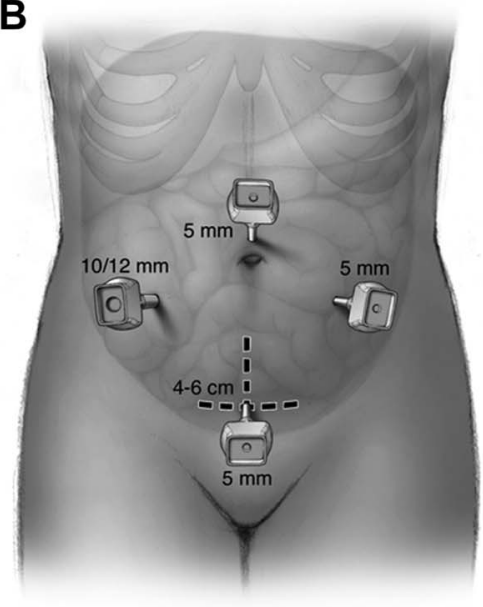

C

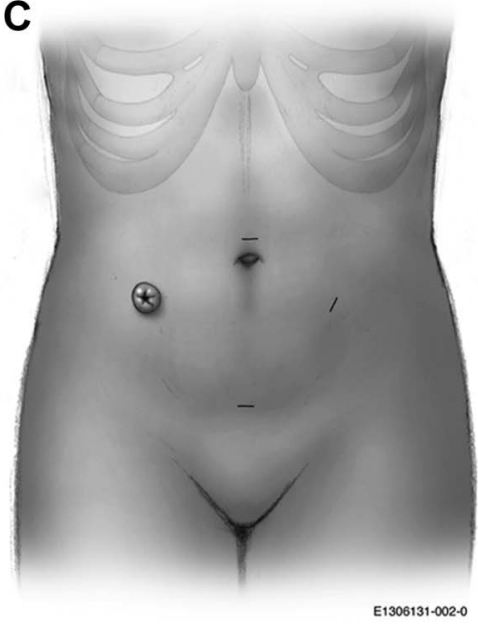

FIGURE 2. MIS approaches to colectomy for Crohn's colitis or CUC; (A) HALS; (B) laparoscopic-assisted surgery; (C) laparoscopic "incisionless" surgery. Reprinted with permission from Holubar SD, Privitera A, Cima RR, et al. Minimally invasive total proctocolectomy with Brooke ileostomy for ulcerative colitis. Inflamm Bowel Dis. 2009;15:1337-1342. Copyright ๔ 2009 Crohn's \& Colitis Foundation of America, Inc. 


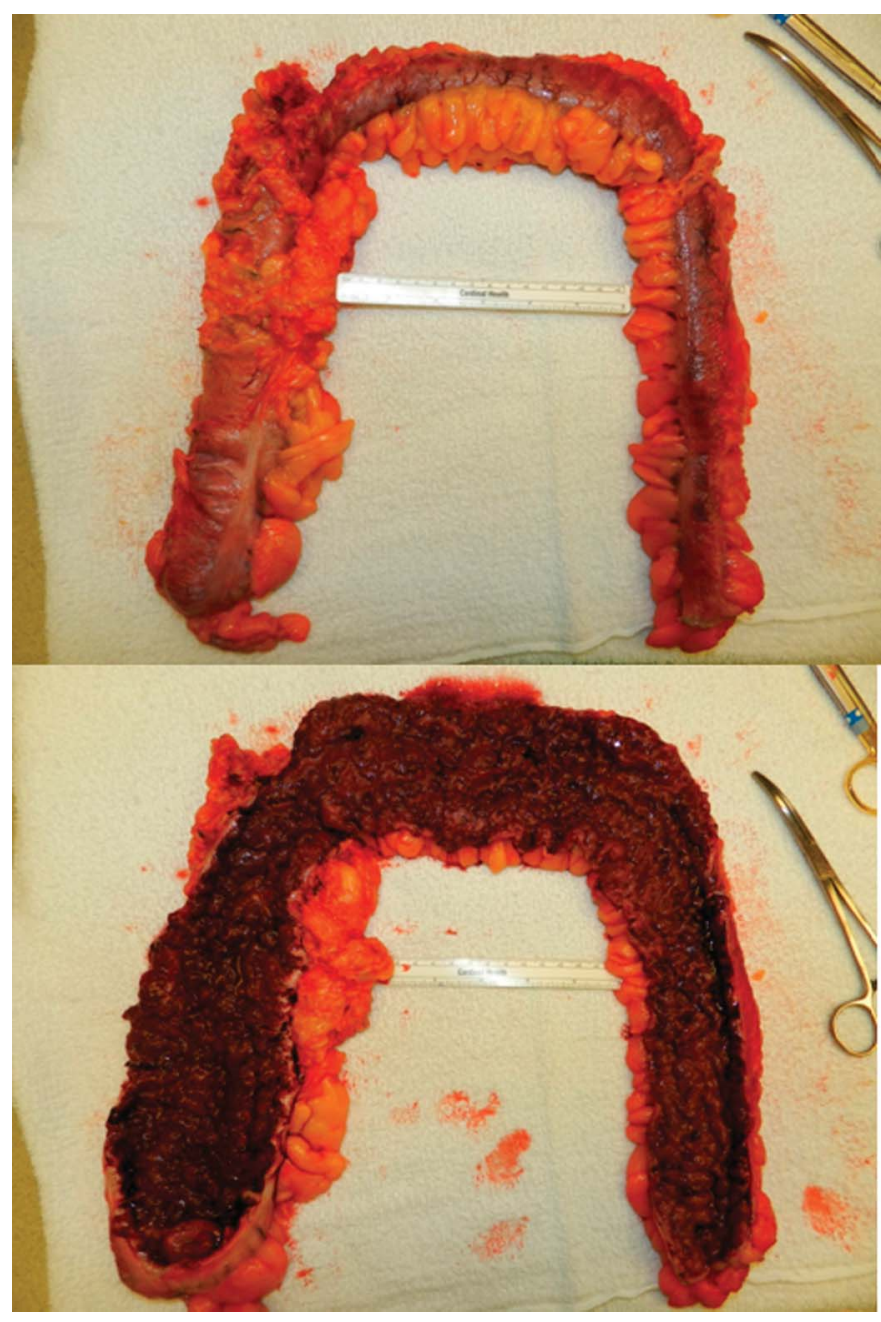

FIGURE 3. Laparoscopic total abdominal colectomy for CUC gross specimen. Top panel: unopened specimen with nontransmural involvement; Bottom panel: opened specimen with pancolitis and pseudopolyposis.

rate of conversion and morbidity are inversely related to surgeon's experience. Unfortunately, as only $6 \%$ of the Nationwide Inpatient Sample patients from 2000 to 2006 underwent laparoscopic resection, clearly open surgery is more likely to be performed overall. This suggests that patients may be more likely to receive MIS surgery if referred to IBD centers/tertiary referral centers with subspecialist surgeons and interdisciplinary teams. In fact, such centers (such as Mount Sinai NYC, Mayo Clinic, Rochester, St. Marks, London) often publish much higher rates of laparoscopy, and although there are contraindications to MIS and patients must be properly selected (Table 2), patients with IBD may benefit from more comprehensive care in addition to the specialized surgical approach.

We will also review current and near-term technologies that enable MIS in patients with IBD. The acceptance of minimally invasive procedures by both patients and surgeons has led to the development of new technologies with the goal of

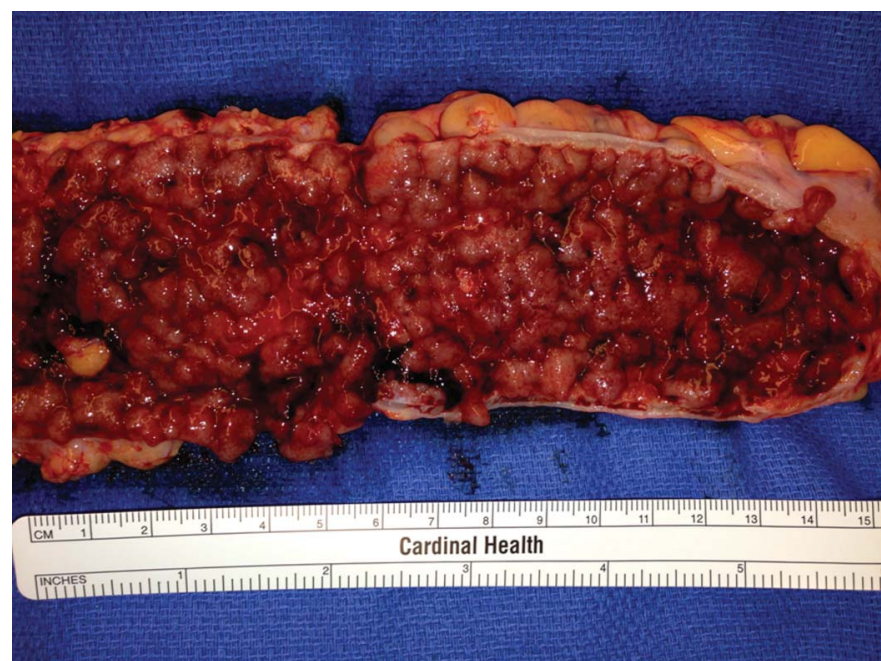

FIGURE 4. Laparoscopic total abdominal colectomy for CUC gross specimen. Pseudopolyposis with thickened bowel wall.

even less invasive approaches, and Table 1 describes the multiple techniques available now and in the immediate future for MIS surgeons and patients. The advent of the single-incision laparoscopic surgery (SILS) devices is enabled by using the 3 - to $5-\mathrm{cm}$ specimen extraction incision as the sole site of laparoscopic access to the abdomen and pelvis, typically with 3 instruments at a time: a camera, a single retractor, and a vessel sealing device or stapler. Another area of technology-enabled surgery is roboticassisted laparoscopic surgery (RALS, Figs. 5 and 6), which provides 3D-HD and articulated/wristed instruments, is an increasingly popular method for proctectomy, allowing improved instrumentation when working in confined spaces, such as the deep pelvis. The clinical application of natural orifice transluminal endoscopic surgery (NOTES) to colorectal disease has not yet fully transpired, although advances in instrumentation has allowed natural orifice specimen extraction after laparoscopic colectomy in select patients. ${ }^{21,22}$

\section{MIS IN CD}

Although the exact etiology of CD is not yet known, it is an autoinflammatory disease with progression and complications, and the majority will require surgical intervention. A full $70 \%$ to $83 \%$ of patients with $\mathrm{CD}$ will require surgery at 10 years from diagnosis (70-83 patients/100), with the most commonly affected site as the ileocecal valve. ${ }^{23,24}$ In addition to the primary operation, postoperative symptomatic relapse rate is as high as $44 \%$ at 10 years after resection and between $25 \%$ and $45 \%$ of those who have previously undergone a resection will require surgical intervention. ${ }^{24,25}$ Surgery, reserved for mechanical or anatomic, always intestinal, complications of $\mathrm{CD}$, can be particularly challenging in these patients as the disease process can lead to pathologyinduced technical difficulties. The presence of transmural inflammation, penetrating (fistulization) disease with abscess, phlegmon, and fistulae, a thickened inflamed mesentery, chronic proximal 
TABLE 1. Definitions of MIS Techniques

\begin{tabular}{|c|c|c|c|c|c|}
\hline Method & Description & Incision size & Advantages & Disadvantages & Applicability to IBD? \\
\hline Laparotomy & $\begin{array}{l}\text { Synonymous with open } \\
\text { surgery }\end{array}$ & $\begin{array}{l}>8 \mathrm{~cm} \text {, typically } \\
12-14 \mathrm{~cm}\end{array}$ & $\begin{array}{l}\text { Typically faster than } \\
\text { most MIS } \\
\text { techniques }\end{array}$ & $\begin{array}{l}\text { Increased pain, hernias, } \\
\text { adhesions }\end{array}$ & $\begin{array}{l}\text { Yes, especially for redo } \\
\text { CD }\end{array}$ \\
\hline $\begin{array}{l}\text { Minimal access } \\
\text { surgery }\end{array}$ & $\begin{array}{l}\text { Open surgery performed } \\
\text { through a wound } \\
\text { protector in an incision } \\
\text { too small for } \\
\text { a surgeons hand; } \\
\text { typically used only for } \\
\text { small bowel } \\
\text { resections, ileocolic } \\
\text { resection, transverse } \\
\text { colectomy, ostomy } \\
\text { construction }\end{array}$ & $3-6 \mathrm{~cm}$ & $\begin{array}{l}\text { Minimal equipment } \\
\text { costs; decreased } \\
\text { pain, hernia, and } \\
\text { adhesions. Can } \\
\text { convert to } \\
\text { laparoscopic, hand- } \\
\text { assisted, or open } \\
\text { surgery easily }\end{array}$ & $\begin{array}{l}\text { Limited ability to } \\
\text { explore/visualize other } \\
\text { parts of the abdominal } \\
\text { cavity }\end{array}$ & $\begin{array}{l}\text { Yes, especially for } \\
\text { isolated small bowel } \\
\text { patients with CD and } \\
\text { CD requiring proximal } \\
\text { fecal diversion with an } \\
\text { ostomy }\end{array}$ \\
\hline $\begin{array}{l}\text { Straight } \\
\quad \text { laparoscopic- } \\
\text { assisted } \\
\text { surgery (Lap) }\end{array}$ & $\begin{array}{l}\text { MIS technique, which } \\
\text { uses laparoscopic ports } \\
\text { with a separate } \\
\text { abdominal specimen } \\
\text { extraction incision }\end{array}$ & $\begin{array}{l}\text { Several 5- to } 12-\mathrm{mm} \\
\text { laparoscopic ports }+ \\
\text { a 3- to } 5-\mathrm{cm} \\
\text { extraction site }\end{array}$ & $\begin{array}{l}\text { Decreased pain, } \\
\text { hernia, and } \\
\text { adhesions }\end{array}$ & $\begin{array}{l}\text { Moderately steep } \\
\text { learning curve }\end{array}$ & $\begin{array}{l}\text { Broadly applicable to } \\
\text { both CD and CUC } \\
\text { (including IPAA), } \\
\text { especially those of } \\
\text { BMI }<30 \mathrm{~kg} / \mathrm{m}^{2}\end{array}$ \\
\hline $\begin{array}{l}\text { Laparoscopic } \\
\text { "incisionless" } \\
\text { surgery }\end{array}$ & $\begin{array}{l}\text { MIS technique, which } \\
\text { uses only laparoscopic } \\
\text { ports with no separate } \\
\text { abdominal incision }\end{array}$ & $\begin{array}{l}\text { Either a transostomy or } \\
\text { transanal/ } \\
\text { transperineal wound } \\
\text { extraction site }+ \\
\text { several } 5 \text {-mm } \\
\text { laparoscopic ports }+ \\
\text { at least one } 12-\mathrm{mm} \\
\text { laparoscopic port }\end{array}$ & $\begin{array}{l}\text { Decreased pain, } \\
\text { hernia, and } \\
\text { adhesions }\end{array}$ & $\begin{array}{l}\text { Limited applicability } \\
\text { (those requiring either } \\
\text { ostomy formation or } \\
\text { total proctectomy) }\end{array}$ & $\begin{array}{l}\text { Typically used for total } \\
\text { colectomy or TPC in } \\
\text { CD or CUC (including } \\
\text { IPAA) in patients with } \\
\text { BMI }<25 \mathrm{~kg} / \mathrm{m}^{2}\end{array}$ \\
\hline RALS & $\begin{array}{l}\text { MIS technique in which } \\
\text { the laparoscopic } \\
\text { camera and } \\
\text { articulating robotic } \\
\text { instruments controlled } \\
\text { by the surgeon sitting } \\
\text { at a console }\end{array}$ & $\begin{array}{l}\text { Several 8- to } 12-\mathrm{mm} \\
\text { robotic ports + several } \\
\text { laparoscopic assistant } \\
\text { ports + a 3- to } 7.5-\mathrm{cm} \\
\text { extraction site }\end{array}$ & $\begin{array}{l}\text { Improved surgeon } \\
\text { ergonomics; no } \\
\text { proven patient } \\
\text { benefit }\end{array}$ & $\begin{array}{l}\text { Significantly increased } \\
\text { cost; steep learning } \\
\text { curve }\end{array}$ & $\begin{array}{l}\text { More commonly used for } \\
\text { proctectomy and } \\
\text { IPAA; indications are } \\
\text { expanding with new } \\
\text { generation robots; may } \\
\text { be advantageous for } \\
\text { MIS proctectomy in } \\
\text { those with BMI }>30 \\
\mathrm{~kg} / \mathrm{m}^{2}\end{array}$ \\
\hline RA-SILS & $\begin{array}{l}\text { MIS technique, which } \\
\text { combines RALS and } \\
\text { SILS }\end{array}$ & $\begin{array}{l}\text { Typically } 3-5 \mathrm{~cm} \\
\text { extraction site; no } \\
\text { additional ports }\end{array}$ & $\begin{array}{l}\text { Decreased pain, } \\
\text { hernia, and } \\
\text { adhesions }+ \\
\text { improved surgeon } \\
\text { ergonomics }\end{array}$ & $\begin{array}{l}\text { Not yet commercially } \\
\text { available }\end{array}$ & $\begin{array}{l}\text { Not applicable at this } \\
\text { time }\end{array}$ \\
\hline
\end{tabular}


TABLE 1 (Continued)

\begin{tabular}{|c|c|c|c|c|c|}
\hline Method & Description & Incision size & Advantages & Disadvantages & Applicability to IBD? \\
\hline NOTES & $\begin{array}{l}\text { MIS technique in which } \\
\text { a rectal or vaginal } \\
\text { incision is used to gain } \\
\text { entrance to the } \\
\text { abdominopelvic cavity } \\
\text { and also to serve as the } \\
\text { specimen extraction } \\
\text { site }\end{array}$ & None & No external incision & $\begin{array}{l}\text { Not yet feasible except as } \\
\text { natural orifice } \\
\text { specimen extraction } \\
\text { with other MIS } \\
\text { techniques for } \\
\text { dissection. Limited } \\
\text { applicability, steep } \\
\text { learning curve }\end{array}$ & $\begin{array}{l}\text { Not applicable at this } \\
\text { time }\end{array}$ \\
\hline
\end{tabular}

With the exception of robotic surgery, laparoscopic and other special operative equipment costs are typically offset by decreased postoperative length of stay.

BMI, body mass index; HALS, hand-assisted laparoscopic surgery; IPAA, ileal-pouch anal anastomosis; NOTES, natural orifice transluminal endoscopic surgery; RALS, robotic assisted laparoscopic surgery; RA-SILS, robotic assisted-single incision laparoscopic surgery; SILS, single incision laparoscopic surgery; TPC, total proctocolectomy.

saccular distension with alternating thickened/floppy bowel wall between diffuse jejunoileal strictures, fragile tissue due to steroids, and adhesions from previous surgery all add independently and incrementally to the complexity of surgical decision-making in these patients.

In a study of the Nationwide Inpatient Sample from 2000 through 2004 , only $6 \%$ of patients with CD who required surgical resection had laparoscopic resections despite decreased length of stay (6 versus 9 d), decreased complications ( $8 \%$ versus $16 \%$ ), decreased mortality $(0.2 \%$ versus $0.9 \%)$, and decreased cost by $\$ 11,138$ compared with open surgery. ${ }^{26}$ With technological advances and increased surgeon experience with minimally invasive techniques, laparoscopic surgery for $\mathrm{CD}$ has increasingly been shown to be a safe and practical approach in selected patients. However, wide regional variation in the use of laparoscopy in this patient population is an issue, and laparoscopy for these at-risk patients clearly remains underutilized.

From a technical perspective, laparoscopic surgeons must take care to find occult segments of disease or proximal strictures because of limited tactile feedback of the instrumentation. In addition, despite the sensitivity of cross-sectional imaging (magnetic resonance and computed tomographic enterography) having greatly improved with present methods, the sensitivity is approximately $70 \%$ to $80 \%$.

Regardless, during laparoscopic surgery, the small bowel in patients with full-thickness fibrostenotic/inflammatory

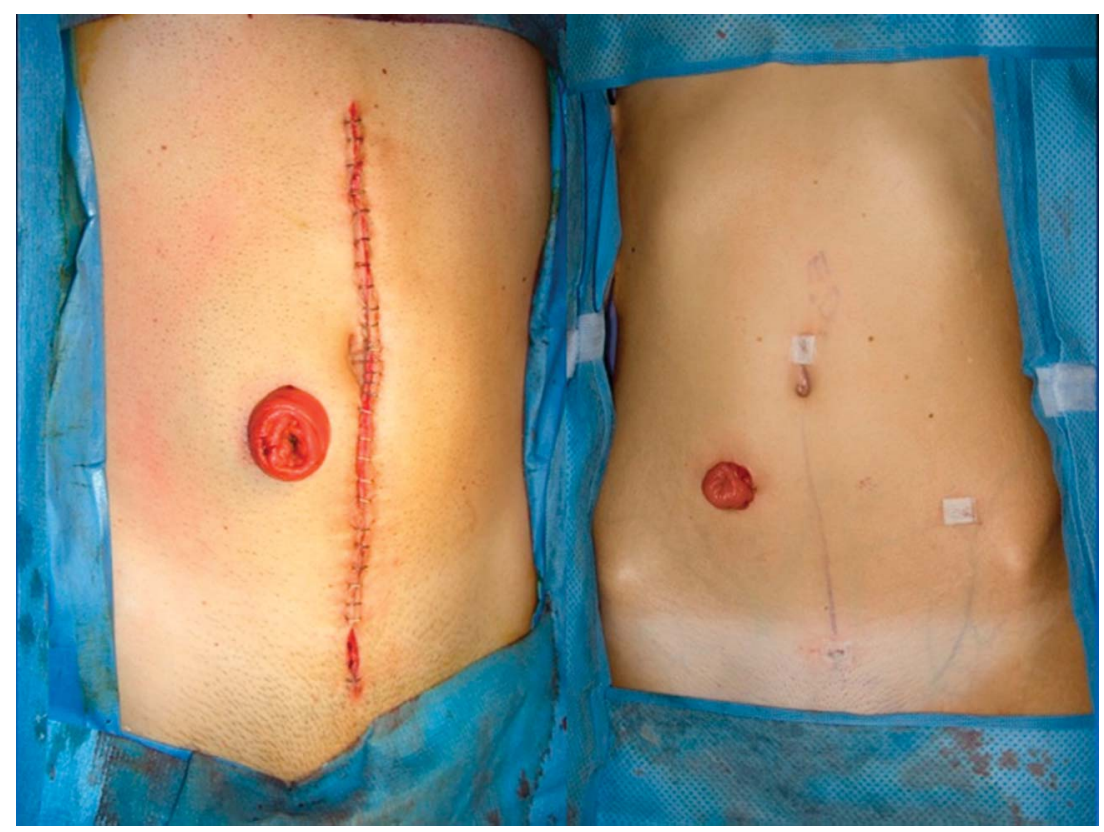

FIGURE 5. Open and laparoscopic abdominal incisions after urgent total abdominal colectomy for CUC. Left panel: laparotomy with staples; right panel: laparoscopic subtotal colectomy with one 12-cm port site hidden in the diverting stoma, three 5-mm suprapubic, and 1 left lower quadrant ports are imperceptible. Left panel courtesy of Holubar; Right panel courtesy of Dozois, May Clinic, Rochester. 


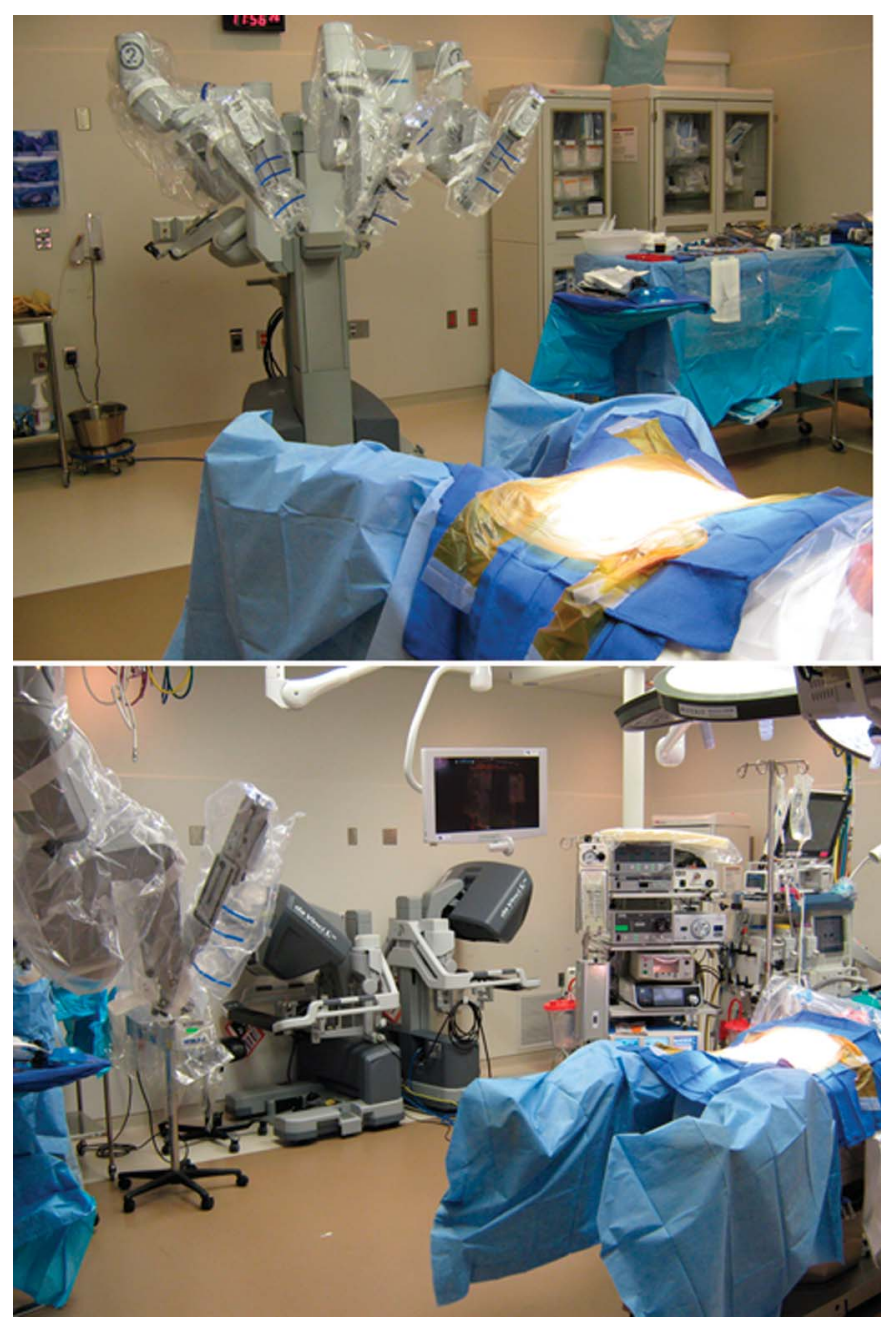

FIGURE 6. Robotic assisted laparoscopic surgery. Top panel: robot awaiting docking in lithotomy position. Bottom panel: robot awaiting docking with 2 surgical 3D consoles in distance. The second console is utilized for a trainee. Images courtesy of Konstantin Umanskiy, MD, University of Chicago.

disease can typically be run during laparoscopy without difficulty, often in high-definition on large monitors and concerning discontinuous areas can still be serially palpated through the specimen extraction incision. In cases of subtle ring-like strictures, the entire small bowel must be palpated by hand often with the aid of an intraluminal device such as the balloon of a long-intestinal Baker tube (or Bakelite ball). In patients with low body mass index (in kilogram per square meter), which is common in CD due to anorexia, lacking severe mesenteric thickening, the entire small bowel can be run by a 3- to 4-cm extraction incision with a wound-protecting device. Longterm follow-up of patients randomized to laparoscopic surgery for $\mathrm{CD}$ demonstrated equivalent reoperation rates compared with open surgery for disease-related and non-disease-related indications. ${ }^{27}$ This argues that laparoscopy does not actually miss clinically significant occult disease.

\section{Uncomplicated Small Bowel and Ileocolic CD}

MIS for primary relatively uncomplicated ileocolic or jejunoileal fibrostenotic CD was the first application of MIS for IBD and has been performed since at least 1992 with early studies demonstrating safety and feasibility. ${ }^{16,28}$ In 2000 with Alabaz et $\mathrm{al}^{29}$ reported a series of 26 patients with ileocolic CD managed laparoscopically compared with an open approach. Longer operative times, shorter hospital stay, and faster return to work were demonstrated in the laparoscopic group with no increased rate of complications. Young-Fadok ${ }^{30}$ also analyzed MIS in 33 consecutive ileocolic patients with CD compared with case-matched controls undergoing open surgery. Despite longer operative times, laparoscopic colorectal surgery has been shown to result in reduced total hospital costs for patients with IBD. ${ }^{30-32}$ In 2001, Young-Fadok $^{30}$ calculated a cost savings of greater than \$3300 USD with the laparoscopic approach. This certainly amounts to even greater cost savings today. Faster return of bowel function and shorter length of stay were again established with a conversion rate of only $5.9 \%$. In 2003, Bergamaschi et al ${ }^{33}$ also described the MIS cohort as having longer operative times $(80 \mathrm{~min})$ and shorter length of stay (from 11.2 to $5.6 \mathrm{~d}$ ) with similar rates of complications (10\% overall). Long-term follow-up revealed decreased incidence of small bowel obstruction with similar rates of recurrence of disease in these same patients. Thus, it has long been recognized that for the patient, physician, and society, MIS surgery for patients with IBD represents high-value care by being more efficacious at a lower cost.

The encouraging results of early adopters was subsequently confirmed by 2 prospective randomized control trials and 5 metaanalyses or systematic reviews comparing laparoscopic to open surgery for ileocolic $\mathrm{CD} \cdot{ }^{27,32,34-38}$ Both randomized control trials had strict inclusion criteria; the Maartense et al randomized control trial excluded patients with a fixed palpable inflammatory mass, prior median laparotomy, prior bowel resection or pregnancy, whereas the Milsom et al included only patients with isolated CD of the terminal ileum with or without cecal involvement. Both studies showed laparoscopic ileocolic resection to be superior in terms of shorter hospital stay, lower postoperative morbidity, and with no difference in quality of life. ${ }^{32,34}$ Similar conclusions have been reached with the meta-analyses conducted to date comparing laparoscopic and open surgery for ileocolic CD. Although laparoscopic resections often take longer to perform, the benefits of reduced length of stay and decreased complications remained significant. ${ }^{27,35-38}$ Additionally, several larger series from the Mayo Clinic and Mount Sinai have echoed these findings. ${ }^{39,40}$ Considering the shorter hospital stay, lower postoperative morbidity, and shorter duration of postoperative ileus, and reduced hospital costs, the laparoscopic approach to surgery for ileocolic CD is firmly established as being a safe, effective, and practical approach. Given the superior short- and long-term results of MIS for CD, it is our opinion that primary uncomplicated ileocolic or small bowel CD should not undergo open surgery unless deemed to have an absolute contraindication to MIS (Table 2) or no appropriate regional resource for advanced laparoscopy is available. 
TABLE 2. Contraindications to Laparoscopic MIS Techniques in Patients with IBD

\begin{tabular}{|c|c|c|}
\hline Category & Contraindication & Mechanism/Reason \\
\hline \multirow[t]{4}{*}{ Lack of domain } & Obliterative peritonitis (frozen abdomen) & Lack of ability to safely establish pneumoperitoneum \\
\hline & Enterocutaenous fistula (ECF) & $\begin{array}{l}\text { Lack of ability to safely establish pneumoperitoneum and need to } \\
\text { resect portion of anterior abdominal wall }\end{array}$ \\
\hline & $\begin{array}{l}\text { Concurrent midline and/or parastomal hernia } \\
\text { especially with concurrent stoma resiting }\end{array}$ & $\begin{array}{l}\text { Need to create/presence of multiple anterior abdominal wall } \\
\text { incisions or defects }\end{array}$ \\
\hline & $\begin{array}{l}\text { Acute (massive) bowel obstruction with proximal } \\
\text { dilation }\end{array}$ & $\begin{array}{l}\text { Lack of ability to safely establish pneumoperitoneum and poor } \\
\text { visualization }\end{array}$ \\
\hline \multirow{3}{*}{$\begin{array}{l}\text { Physiologic inability to } \\
\text { tolerate pneumoperitoneum }\end{array}$} & Preload dependent cardiac function & Pneumoperitoneum-related decreased venous return \\
\hline & Severe COPD & $\begin{array}{l}\text { Decreased pulmonary function related to flattening of the } \\
\text { diaphragm and increased } \mathrm{pCO}_{2}\end{array}$ \\
\hline & Septic shock & Unstable physiology, need for expeditious source control \\
\hline \multirow[t]{4}{*}{ Technical } & Feculent peritonitis & $\begin{array}{l}\text { Inability to adequately remove thick fecal contamination from } \\
\text { abdominopelvic cavity }\end{array}$ \\
\hline & $\begin{array}{l}\text { Uncontrolled coagulopathy (e.g., plavix or severe } \\
\text { malnutrition) }\end{array}$ & Inability to safely maintain visualization \\
\hline & Lack of surgeon experience & Lack of training \\
\hline & Lack of proper equipment & Lack of resources \\
\hline
\end{tabular}

\section{Complicated Small Bowel and Ileocolic CD}

Early reports of laparoscopic surgery for $\mathrm{CD}$ reserved the procedure for "uncomplicated" patients. ${ }^{28}$ More recently, however, and perhaps concomitant with increasing surgeon experience with more advanced instrumentation, the trend has been towards laparoscopy for a wider array of patients, including those with recurrent or fistulizing disease. In 2003, Seymour and Kavic ${ }^{20}$ reported a series of 17 MIS cases in patients with complicated $\mathrm{CD}$, defined as the presence of fistulas, multiple, or long segment disease, abscesses, and previous operations. They found that although operative time was nearly doubled, no patients were converted to open and morbidity rates were equivalent to laparoscopic resections of limited ileal disease. Likewise, Goyer et a ${ }^{17}$ compared 54 complex patients with $\mathrm{CD}$, defined as recurrent or complicated by abscess and/or fistula, to an uncomplicated cohort. No differences were noted in overall postoperative morbidity, although operative times were longer, conversion rates were higher, and there was an increased use of a temporary stoma. The latter differences likely reflect the sicker and more complex patient population rather than necessity of a stoma secondary to laparoscopy; importantly, MIS was still possible in many of these most complex patients. Most recently in 2013, Beyer-Berjot et a $\mathrm{a}^{41}$ published a series on complex enterovisceral fistulae in a cohort of patients with $\mathrm{CD}$, including patients with ileosigmoid, ileocolic, and enterovesicular fistulae. No differences were noted in operative time, conversion rate, or postoperative morbidity.

In a large series of 434 patients at the University of Toronto, those with penetrating disease undergoing open or MIS resection were more likely to require parenteral nutrition, have a longer hospital stay, require an ostomy or a subsequent resection, have a postoperative abscess or leak, and less likely to have laparoscopic surgery. ${ }^{42}$ These data highlight the severe disease activity and complexity of these surgical patients. However, despite those with penetrating disease undergoing open surgery more often than those with nonpenetrating $\mathrm{CD}$, many of these were still safely managed with MIS approaches, thus conferring the benefits of MIS to a group of complex and ill patients. Although the appropriate selection criteria are still evolving and some patients will continue to require open surgical approaches, MIS can be safely applied to a more complex group of patients with $\mathrm{CD}$.

Alves et $\mathrm{al}^{43}$ examined the risk factors necessitating conversion from laparoscopic to open surgery in IBD. Risk factors for conversion included more than 3 acute flares of $\mathrm{CD}$ before surgery, male gender, preoperative immunosuppressive medications, intra-abdominal abscess or fistula, and resection of an additional intestinal segment. In this series of patients, conversion to open surgery occurred in 30\% of laparoscopic ileocolic resections. However, as surgeons gain experience and overcome the steep technical learning curve, conversion rates fall. In a metaanalysis by Tilney et $\mathrm{al}^{38}$ of 783 patients with ileocolic $\mathrm{CD}$, only $6.8 \%$ of laparoscopic surgeries were converted to open surgeries. Thus increasingly, even patients with complicated presentation with abscess and fistula can be offered the benefits of an MIS approach.

\section{Recurrent lleocolic CD}

MIS for recurrent ileocolic disease has also been proven to be safe and these patients too benefit from the MIS approach. Recurrent disease and a reoperative right lower quadrant poses challenges of abdominopelvic adhesions and altered anatomy, making the MIS approach more difficult a priori. Although there are fewer series including only redo ileocolic $\mathrm{CD}$, data can be 
extracted from several previously mentioned series that include reoperative patients and often pool this group with other complex $\mathrm{CD}$, such as enteric fistula. Goyer et al, $\mathrm{Wu}$ et al, and Seymour and Kavic all demonstrated feasibility in these reoperative patients. ${ }^{17,20,44}$ Length of stay varied compared with those with limited ileal disease, and there was no increased morbidity. Pinto et $\mathrm{al}^{45}$ comparing 50 reoperative patients to those undergoing a primary resection also showed similar benefits to the MIS group. It thus seems that the benefits of MIS surgery in CD are not sacrificed when the surgery is performed for recurrent versus primary disease. In a 2010 study of 40 patients undergoing laparoscopic resection for recurrent ileocolic disease, Holubar reported a Mayo Clinic series, and $75 \%$ of redo ileocolic patients were successfully completed laparoscopically. ${ }^{19}$ The benefits of attempting laparoscopy in this group included a shorter time in days to soft diet and a shorter length of stay ( 4 versus $7 \mathrm{~d}$ ). That study cited a $25 \%$ conversion rate, and all conversions were felt secondary to adhesions.

The main risk of MIS for recurrent ileocolic disease is conversion to open surgery. This occurred in approximately $0 \%$ to $25 \%$ of well-selected redo ileocolic patients. ${ }^{16,19,20,44}$ In a series that spanned decades, the conversion rate was found to be as high as $61 \%$ in the cohort for patients exclusive of primary resections. ${ }^{16}$ In fact, the Cleveland Clinic published a series of patients who underwent MIS resection after a previous laparotomy and found only a $12 \%$ conversion rate to open surgery. ${ }^{46}$ The most commonly cited indication for conversion to open surgery included adhesions, cited in $80 \%$ of the converted patients in that series and $47 \%$ in the Edden series. ${ }^{16,19}$ Interestingly, Edden et al did not find that previous resection predicted conversion to laparotomy. These studies suggest that if local expertise exists, MIS should be attempted in these redo cases, and the majority of patients will benefit despite recurrent disease being a risk factor for conversion to open surgery.

\section{Crohn's Colitis}

Although Crohn's colitis is less common than ileocolic $\mathrm{CD}$, occurring in $30 \%$ versus $75 \%$ of patients with $\mathrm{CD}$, respectively, the benefits seen after an MIS approach to primary, complicated, and redo ileocolic resection have also been reported in patients with Crohn's colitis. Compared with patients with CUC, patients with Crohn's colitis have a higher incidence of prior resections and obviously a higher incidence of penetrating disease with fistulae and abscesses than CUC-reported outcomes. Holubar et $\mathrm{al}^{47}$ reported a Mayo Clinic series of 92 patients with Crohn's colitis who were managed laparoscopically. These patients were treated with aggressive medical management $(35 \%$ infliximab, 54\% corticosteroids, 62\% immunomodulator) and $11 \%$ had prior intestinal resection. Despite advanced disease activity, only $16 \%$ were unable to be managed laparoscopically. Postoperative stays were short (4 d), and only perianal disease predicted conversion to open surgery likely because of difficult proctectomy or need for plastics reconstruction. Comparison studies have also demonstrated similar benefits. Umanskiy et $\mathrm{al}^{48}$ at the University of Chicago described 125 patients with Crohn's colitis in a comparative analysis, of which $44 \%$ were managed with MIS. Conversion to open surgery was $10.9 \%$. Shorter operative time, less operative blood loss, earlier return of bowel function, and shorter length of stay were demonstrated. Finally, the Cleveland Clinic also described their series of 27 patients with Crohn's colitis patients with case-matched controls. ${ }^{49}$ Similar benefits were demonstrated compared with open surgery with earlier return of bowel function and shorter length of stay, yet operative times were longer.

\section{Perianal Disease}

The final application of MIS surgery to patients with IBD is the palliation of symptoms due to fistulizing disease with deep painful fissures, swollen and draining fistulae, sinus tracts, and perianal and perirectal abscesses. For these patients, diversion of the fecal stream may allow less hostile/more optimal conditions for healing. These patients are ideal for SILS or 2- to 3-port 5-mm laparoscopy (Figure 2C) with very short operative times, typically less than 30 minutes, and exceptionally low morbidity. The initial MIS approach also facilitates stoma reversal as few if any adhesions are typically encountered. Little has been written about this approach.

\section{CHRONIC ULCERATIVE COLITIS}

CUC is estimated to affect more than 500,000 persons in North America, at an estimated annual cost of $\$ 2.1$ billion in health care dollars per year, ${ }^{50}$ and an estimated $20 \%$ to $30 \%$ of patients with CUC will eventually require surgical intervention. ${ }^{51}$ Ileal pouch-anal anastomosis (IPAA), also known as restorative proctocolectomy (RPC) is the surgical gold standard for CUC. First described by Sir Allen Parks at St. Marks Hospital London in the early $1980 \mathrm{~s},{ }^{52}$ construction of IPAA offers long-term restoration of intestinal continuity without need for permanent ileostomy in the majority, with pouch survival of $>90 \%$ at 20 years. ${ }^{53}$ If RPC is not possible due to anatomic or functional reasons (such as sphincter damage or pelvic floor dysfunction) or contraindicated due to severe medical comorbidity or simple patient preference, then total proctocolectomy (TPC) with end ileostomy may offer patients with functionally crippling symptoms improved quality of life. The American Society of Colon and Rectal Surgeons guidelines describe the indications for elective surgical management of UC. ${ }^{54}$ Medically refractory CUC (82\%), intolerance to or nonadherence with medical treatment, and neoplasia (DALM lesions and colorectal cancer, 18\%) are common indications for surgery. ${ }^{55}$ This procedure also offers a definitive cure for the colonic manifestations of CUC. MIS for UC was first reported by Peters ${ }^{56}$ in 1992, describing a laparoscopic TPC with ileostomy in 2 patients.

In the 21 st century, RPC with IPAA has become the treatment of choice for appropriate patients with CUC, and laparoscopic techniques are becoming standard and preferred. IPAA is most commonly performed in a 2-stage or 3-stage 
approach. In a 2-stage approach, the first stage is a TPC with IPAA and diverting loop ileostomy, with the second stage being the ensuing ileostomy closure. Only rarely, in the most highly selected patients is a single-stage approach undertaken because of the relatively high rate of anastomotic leakage, dehiscence, or pelvic abscess $(15 \%)$ and long-term inflammation-/infectionmediated decreased pelvic floor compliance, which often inhibits optimal or even acceptable pouch function. ${ }^{57}$ A 3stage approach begins with a total abdominal colectomy (also called subtotal colectomy), subsequent completion proctectomy with IPAA, and temporary diverting loop ileostomy, followed by ileostomy closure. ${ }^{58} \mathrm{~A}$ variation of the 3 -stage procedure is modified 2-stage procedure in which the first procedure is a total colectomy, while the second stage is a completion proctectomy with IPAA construction without temporary diverting loop ileostomy. ${ }^{59}$

\section{MIS Colectomy for Severe-to-fulminant CUC}

In the setting of severe-to-fulminant acute presentations of CUC when the patient is most ill, the surgical goals remove the bulk of diseased bowel (i.e., total colectomy), preserve the option for reconstruction after recovery and withdrawal of treatment medications, and restore patient health (weight gain, reversal of anemia). Subtotal colectomy or total abdominal colectomy with end ileostomy and Hartmann closure or mucous fistula of the distal bowel is a safe and effective approach in this setting. ${ }^{58,60-62}$ A systematic review of 29 studies published from 1975 to 2007 included 2714 patients with severe acute colitis who underwent colectomy. ${ }^{63}$ Including only the studies published after 1995, the morbidity and mortality were $51 \%$ and $2 \%$, respectively, emphasizing the poor health of this patient cohort. Multiple studies have compared laparoscopic and open approaches for abdominal colectomy. Laparoscopic management of severe CUC has been demonstrated to be both safe and feasible, without increased morbidity with MIS approaches. ${ }^{58,64-69}$ Although operative times were often longer with MIS, operative times have decreased over time as surgeons have gained more experience with this approach. Return of bowel function and length of stay was reduced after laparoscopic colectomy in several studies, including in the pediatric population. ${ }^{65,67,68,70,71}$ Comparison of the hand-assisted laparoscopic technique to straight laparoscopic abdominal colectomy has shown equivalence between these techniques when assessing morbidity and postoperative recovery but with decreased operative time with the hand-assisted technique. ${ }^{72,73}$ No study has yet analyzed laparoscopic approaches for the surgical management of severe acute colitis during emergent indications, such as megacolon and perforation. Poor exposure due to a dilated colon or intraperitoneal contamination and tissue friability make MIS approaches quite difficult in these settings. Laparoscopic approaches should be cautioned to expedite care and not worsen the patient's clinical condition with possible further intraperitoneal feculent spillage, and the presence of megacolon is considered to be an absolute contraindication to MIS.

\section{2- Versus 3-stage IPAA}

The conservative 3-stage approach to ulcerative colitis is often applied to patients presenting with severe-to-fulminant disease refractory to multiple medications. ${ }^{74}$ The benefit of a 3 -stage approach is deferral of the pelvic dissection and risk of anastomotic leak until the patient's clinical condition has improved, thereby reducing operative time, operative blood loss, and risk of septic complications in patients with already poor health. The feasibility and safety of MIS in the 3-stage approach is well documented. In 2000, Marcello et a $1^{75}$ compared 20 consecutive laparoscopic IPAA for both UC and familial adenomatous polyposis (FAP) to casematched open IPAA patients. Although operative time was longer and morbidity was equivalent, return of bowel function and length of stay favored the MIS approach. Larson et al ${ }^{76}$ later reported a series of 100 laparoscopic IPAA and 200 case-matched control patients. Laparoscopic IPAA patients had faster return of bowel function, decreased narcotic use, decreased length of stay with equivalent morbidity, and readmission rates. Similar benefit was found in the pediatric literature, with decreased incidence of postoperative complications and small bowel obstruction after laparoscopic IPAA. ${ }^{77}$

Several meta-analyses or systematic reviews further support the use of MIS approaches to IPAA. In 2006, Tan et $\mathrm{al}^{78}$ performed a meta-analysis comparing laparoscopic IPAA to open IPAA examining 10 studies including 387 patients. Operative time was found to be equivalent, but length of stay and complications were reduced with the MIS approach. Several years later in 2010 , a meta-analysis by $\mathrm{Wu}$ et a $\mathrm{l}^{79}$ of 16 studies comparing laparoscopic to open IPAA also demonstrated decreased length of stay but increased operative times. Return of bowel function, septic complications, anastomotic leak rates, operative blood loss, and mortality were equivalent. Interestingly, overall complications were decreased. A Cochrane review of 11 studies including 607 patients demonstrated longer operative times but equivalent rates of postoperative bowel recovery, complications, reoperations, readmissions, and mortality. ${ }^{80}$ Analysis of laparoscopic and open IPAA from the NSQIP registry revealed a marked reduction in both major and minor complications (odds ratio, 0.67 and 0.44 , respectively). ${ }^{81}$ Collectively, these data argue that despite the technically challenging and longer operation, a minimally invasive approach is a safe and effective treatment with the added benefits of faster recovery of gastrointestinal function, shorter hospital length of stay, and no increase in anastomotic complications, as well as decrease in overall complications. At the present time, in the biologic era and due to surgeon's concern over the increased rates of septic complications from biologic agents, ${ }^{82}$ the 3 -stage approach is en vogue, although some question its overuse. ${ }^{83}$ The issue of whether biologics agents do indeed increase septic complications after surgery for CUC has yet to be definitely answered, although a multicenter observational trial is likely to give the best available evidence on this topic to date within the next several years (PUCCINI trial).

Unlike the more conservative 3-stage approach to ulcerative colitis, the standard 2-stage approach may be favored in some 
clinical scenarios, thus eliminating a third operation and the resulting recovery. As insinuated, no randomized trial or highquality evidence exists comparing the 2-stage and 3-stage approaches. Pandey et $\mathrm{al}^{74}$ examined the use of laparoscopic 2stage and 3-stage pouches at the University of Chicago. Patients in the 3-stage group were more likely to have received aggressive medical therapy including biologic therapy and corticosteroids. Overall complications were similar between the groups, yet infectious complications were higher in the 2 -stage group (38\% versus $21 \%$ ). The authors concluded that caution must be emphasized when a 2-stage approach is applied to patients with CUC, even when medical management regimens are not the most aggressive.

Because of concern over differences in technique between open and MIS approach, mainly due to the lack of a laparoscopic true 90-degree right angle stapling device leading to an asymmetrical anorectal cuff staple line, several studies have evaluated functional outcomes of the minimally invasive IPAA. Polle et al ${ }^{84}$ demonstrated improved body image and cosmesis scores in the female patients undergoing laparoscopic IPAA. Functional outcomes and quality of life scores were equivalent to open IPAA in both male and female patients. Dunker et $\mathrm{al}^{85}$ also found improved body image and cosmesis with equivalent functional results and quality of life after laparoscopic IPAA. In 2009, Fichera et al ${ }^{86}$ analyzed a cohort of 179 laparoscopic and open IPAA patients and found similar frequency of bowel movements and rates of incontinence between groups. Incisional hernia rates were reduced in the laparoscopic group, likely secondary to the increased use of a Pfannenstiel incision in the laparoscopic cohort. An early experience of 23 patients undergoing the modified 2-stage approach was reported in 2005. ${ }^{59}$ There were no anastomotic complications. Postoperative number of bowel movements, use of hypomotility agents, and fecal incontinence were equivalent to 3 -stage IPAA. Although not performed laparoscopically in this study, results can likely be extrapolated to a minimally invasive modified 2-stage approach; however, one must be careful to make further conclusions as this version of a 2-stage approach is not often recommended. Overall, the use of minimally invasive techniques in IPAA does not alter shortterm or long-term functional results but likely improves patientperceived considerations of body image and cosmesis in this mostly young patient population.

\section{1-Stage IPAA}

Single-stage IPAA may be performed in only very carefully selected cases. Most small series reporting experience with singlestage IPAA combine patients with FAP and CUC. Patients with FAP are quite dissimilar to CUC as they typically do not harbor an inflammatory component to their disease state, and their baseline bowel function is typically more normal, whereas baseline bowel function for patients with CUC is typically quite abnormal. Therefore, one must be careful to extrapolate FAP data to IBD. Also, the patients selected for a single-stage IPAA are generally the best-of-the-best with good nutrition, favorable body habitus, lack of inflammatory or infectious complications of the disease preoperatively, and typically not on immunosuppressive medical regimens. Ky et $\mathrm{al}^{87}$ described results following 1-stage laparoscopic IPAA in carefully selected patients (29 with UC, 3 with FAP). Two patients required reoperation in the perioperative period for septic complications, one undergoing a temporary ileostomy and the other for transpouch drainage. A total complication rate of $34 \%$ was noted, which is similar to many other series of open RP. Also out of Mount Sinai, NYC, Gorfine et $\mathrm{al}^{88}$ published a large series comparing the experience of 1 -stage $(n=74)$ or 2 -stage $(n=69)$ open IPAA for CUC and FAP. Patients were very carefully selected for 1-stage IPAA, met strict preoperative guidelines, and had optimal baseline operative characteristics. No differences were noted in pelvic abscess or IPAA suture line dehiscence rates in this highly selected group of open IPAA patients. No comparison studies have been performed between 1- and 2-stage laparoscopic IPAA to date, because of the 1-stage numbers being rate limiting. Although the 2 studies referenced above do not highlight increased rates of pelvic sepsis in the carefully selected patient cohorts, this is certainly a concern of critics of this approach. Perioperative pelvic septic complications worsen long-term IPAA functional results. ${ }^{89,90}$ The 2-stage IPAA with fecal diversion or the 3 -stage IPAA do not eliminate the pelvic septic complications, but they do limit the infectious burden to the pelvis, thereby possible improving IPAA functional results. Therefore, single-stage IPAA should only be considered for those patients with UC who are not on immunomodulator or biologic therapy, on minimal to no steroids, are not obese and otherwise with favorable body habitus, and are without other nutritional derangements or anemia; furthermore, operative characteristics must also be considered and include a perfect IPAA construction, a tension-free anastomosis, and no excessive blood loss or other operative concern. It is the authors opinion that this approach should only rarely and cautiously be used, if ever, as a septic complication can result in a noncompliant pelvic floor, poor-pouch function, and need for permanent, as opposed to a temporary ileostomy.

\section{MIS Total Proctocolectomy with End Ileostomy}

An alternative to restoration of intestinal continuity is TPC with permanent end ileostomy. Although RPC has been favored over the last few decades, TPC "may be considered the benchmark procedure for which all other operations are compared." 54 A TPC with end ileostomy is the procedure of choice for patients who may choose not to undergo a RPC and for others who may be at significant risk for pouch failure, such as patients with poor anal sphincter function, prior anoperineal disease, morbid obesity, or limited physiological reserve from medical comorbidities. Patients may first undergo a laparoscopic abdominal colectomy with preservation of the rectum, followed by proctectomy as a second surgery. Alternatively, in patients without contraindications, a TPC with end ileostomy may be performed in a single surgery. Mayo Clinic demonstrated feasibility of minimally invasive 
approaches in 44 patients, describing several techniques for laparoscopic TPC with end ileostomy with only a $4.6 \%$ conversion rate to open surgery. ${ }^{55}$ Holder-Murray et $\mathrm{al}^{91}$ described the largest series of totally laparoscopic proctocolectomy with end ileostomy for patients with IBD. In this series, the perineal incision was used as the extraction site, thus eliminating an additional incision and its associated complications, such as infection, adhesions, and hernia formation. Operative blood loss and length of stay were reduced, and earlier return of bowel function was noted in the laparoscopic group. Also, wound infection and parastomal hernia were $0 \%$ and $6 \%$ in the laparoscopic group versus $23 \%$ and $10 \%$ in the open group, respectively.

\section{MIS in CUC Complicated by Primary Sclerosing Cholangitis}

Primary sclerosing cholangitis (PSC) is frequently associated with IBD especially CUC. Progressive inflammation leads to biliary fibrosis and cirrhosis and can eventually and ultimately necessitate liver transplantation. The presence of PSC and/or a liver transplant is not a contraindication to laparoscopic surgery, although portal hypertension will play a role in surgical decisionmaking, including risk of stomal varices. Open proctocolectomy and IPAA have been described in PSC before and after liver transplantation by the Mayo Rochester group, but limited studies exist on MIS in this group. Two cases of hand-assisted laparoscopic surgery (HALS) colectomy after orthotopic liver transplant in patients with CUC have been described, and we recently described the first reported case of straight laparoscopic total abdominal colectomy with end ileostomy after orthotopic liver transplantation for PSC in a patient with UC. ${ }^{92}$

\section{INNOVATIVE MINIMALLY INVASIVE SURGICAL TECHNIQUES}

\section{Single-incision Laparoscopic Surgery}

A single-incision laparoscopic approach for the surgical patient with IBD is enticing and currently in vogue. Further minimizing already MIS, the SILS approach uses only 1 incision through which an operating platform allows several working instruments in addition to the laparoscopic camera. SILS therefore offers improved cosmesis by eliminating several 5- to $12-\mathrm{mm}$ incisions in the abdominal wall as in multiport laparoscopy. Although high-quality evidence supporting superiority of a single-incision approach over multiport laparoscopy does not exist, current studies demonstrate feasibility and applicability to both primary and recurrent resections in selected patients when performed by surgeons with extensive laparoscopic experience.

Rijcken et $\mathrm{al}^{93}$ previously reported the efficacy and safety of SILS ileocecectomy in 22 patients with CD over case-matched control patients. The authors demonstrated no difference in conversions to open surgery, perioperative outcomes, complications, or postoperative pain scores and therefore concluded that SILS colectomy was safe but offered no benefit. More recently, Moftah et $\mathrm{al}^{15}$ analyzed the use of SILS for patients with complex and recurrent $\mathrm{CD}$. Over a 36 -month period, 28 patients whose procedures were initiated by single-port laparoscopy were studied, including those needing urgent intervention $(n=15)$, those with prior abdominal operation $(\mathrm{n}=8)$, obstruction $(\mathrm{n}=7)$, mass $(\mathrm{n}=$ $6)$, fistula $(n=6)$, and/or abscess $(n=4)$. Surgeries included redo ileocolic resections or segmental colectomy. Conversion rate to open surgery was not unreasonable at $15 \%$ in this series. These studies established the safety and efficacy for SILS segmental colectomy in patients with CD.

The SILS approach has also been used successfully in surgery for CUC. In 2011, Fichera et $\mathrm{al}^{94}$ reported a series of 10 patients with medically refractory disease who underwent SILS total abdominal colectomy with end ileostomy. Results were comparable with case-matched laparoscopic-assisted and handassisted laparoscopy patients with shorter duration of surgery and earlier resumption of a solid diet, although these benefits are questionable based on study design. Certainly, there were no adverse outcomes, thus demonstrating feasibility. Gash et $\mathrm{al}^{95}$ reported a series of 10 RPC IPAA cases with the SILS port placed at the ileostomy site. No major complications were noted, and short-term functional results were also good.

Several systematic reviews or meta-analyses have been performed for SILS colectomy for colon and rectal diseases. Maggiori et $\mathrm{al}^{96}$ analyzed more than 1000 patients from more than 64 studies and found a decreased size of skin incision and a shorter length of stay. Others have demonstrated similar benefits or at least equivalence but have also demonstrated decreased operative blood loss and increased conversion rate to open surgery compared with multiport laparoscopy. ${ }^{97-100}$ Although technically more challenging, SILS seems to be a reasonable approach to the surgical management of patients with IBD, capable of minimizing extent of incisions, while maintaining the benefits and short-term outcomes of laparoscopy and improving cosmesis slightly. Critics, i.e., multiport laparoscopists, feel the morbidity of the additional 5-mm ports to be negligible, thus SILS is not justified especially given it increased technical demands. Additional long-term studies are warranted to fully explore the benefits that are yet to be proven objectively with this maximally MIS approach to IBD surgery.

\section{Robotic-assisted Laparoscopic Surgery}

Robotic surgery, also presently in vogue, is an evolution of minimally invasive techniques, which uses a robotic platform and instrumentation that is controlled by a surgeon sitting at a console detached from the patient. RALS offers the surgeon improved laparoscopic manual dexterity with wristed instrumentation and computer technology that optimizes delicate and intricate movements, improves surgeon ergonomics, and improves visualization of the abdominopelvic cavity in true 1080 pixel high-definition 3-dimensions. Limitations of RALS surgery include significantly increased operative cost (presently only 1 vendor) and time, need for additional training and proctoring, 
a steep institutional and surgeon learning curve, and no proven benefit over laparoscopic surgery. Nonetheless, RALS has been demonstrated to be both feasible and safe in colon and rectal surgery for both benign and malignant diseases, and the incidence of robotic procedures is increasing markedly. Despite increasing prevalence, to date, no benefits over laparoscopic surgery have been reported. Rather proponents for robotic surgery argue that improved visualization and dexterity may decrease the number of conversions to open surgery during proctectomy. Baik et al ${ }^{101}$ demonstrated a conversion rate to open surgery for laparoscopic low anterior resection of $10.5 \%$ versus $0 \%$ for robotic resection. Despite lack of benefit with robotic colon and rectal surgery, there also have been no increased risk of complications, length of stay, morbidity, or mortality when compared with laparoscopic techniques, thus demonstrating continued improved patient outcomes over open surgery. ${ }^{101-104}$

The narrow confines of the pelvis and bulk of the mesorectum can limit the use of standard laparoscopic instruments, and therefore the merits of robotic surgery are most applicable to proctectomy. Robotic total mesorectal excision for rectal adenocarcinoma is the most studied robotic colon and rectal procedure. Although a randomized controlled trial is ongoing (none reported to date), proctectomy for rectal cancer has demonstrated similar intraoperative and postoperative complication rates, short-term outcomes, and oncologic equivalence. ${ }^{6-9}$ Studies of robotic surgery in specifically patients with IBD are sparse and limited. Nevertheless, its use in RPC with IPAA in patients with CUC seems logical. Several small series demonstrate that RPC with IPAA or completion proctectomy in patients with IBD offers similar perioperative complications, short-term outcomes, and short-term functional results when compared with laparoscopic techniques. ${ }^{105-107}$

Robotic surgery has also been applied to right colectomy, as this operation is limited to a single quadrant of the abdomen (all prior models needed to be redocked to change quadrants, whereas the newest generation has overcome this limitation); this technique carries applicability to patients with $\mathrm{CD}$ requiring an ileocecectomy or ileocolic resection. Case series of robotic right colectomy include patients with both benign and malignant diseases and demonstrate no benefit and no adverse outcomes when compared with laparoscopy. ${ }^{108-111}$ A single randomized controlled trial comparing standard laparoscopy versus robotic surgery for right colon cancer demonstrated similar perioperative and postoperative outcomes but with significantly higher cost associated with robotic surgery. ${ }^{112}$ In 2014 , Kim et al ${ }^{113}$ performed a systematic review of 69 studies of robotic colon and rectal surgery and concluded that robotic surgery showed equivalent short-term outcomes but was associated with longer operative times and higher cost.

Further pushing the envelope, robotic techniques have been used with the SILS approach. Juo et $\mathrm{al}^{114}$ described their experience with a single patient undergoing a robotic SILS total abdominal colectomy for CUC. In 2009, Ostrowitz et al ${ }^{115}$ published their series of 3 patients who underwent robotic SILS right hemicolectomy with an extracorporeal anastomosis by the 4-cm incision used for the SILS port. Current robotic techniques and instrumentation allow for an intracorporeal anastomosis, yet this is difficult in colonic surgery and a specimen extraction incision is still necessary. The ability to perform an intracorporeal anastomosis may limit the need for a small midline incision, thus allowing for a small incision off the midline (such as a Pfannensteil), which in turn may limit the higher incisional hernia rate seen with midline incisions. We anticipate that as the robotic instruments become smaller and more flexible, in the near future, robotic surgery and laparoscopic surgery will merge and become indistinguishable, and thus will be applied broadly to patients with IBD.

\section{Natural Orifice Transluminal Endoscopic Surgery}

Entirely NOTES colectomy has yet to be performed in a live human patient. Whiteford et $\mathrm{al}^{116}$ has demonstrated feasibility in cadaveric models, and animal models have also been demonstrated. In some small series, NOTES has been used solely as an extraction tool with minimally invasive surgical techniques used for the resection and anastomosis and the specimen extracted through the vagina, anus, or a defect created in the rectum. However, the applicability of NOTES extraction to patients with IBD is yet to be realized for a myriad of reasons. NOTES may be unnecessary, as many of these patients require an ostomy and therefore an abdominal wall incision, thus negating the potential benefits of the lack of abdominal wall incisions with true NOTES. Barriers to transanal or transrectal extraction include anal stenosis, small caliber rectum, active anorectal disease, and bulky mesentery or specimen. Concerns related to NOTES extraction include intraabdominal contamination leading to pelvic sepsis and worsening incontinence. Difficulty with continence secondary to diarrhea, prior anal disease, previous anal surgery, or obstetrical trauma may only be worsened in both patients with CUC and $\mathrm{CD}$ because of concerns for potential sphincter trauma during anorectal specimen extraction. Furthermore, patients with CD may be more likely to develop fistula to the NOTES site. Transvaginal specimen extraction has proven safe in a few small series of patients without IBD; however, women of childbearing age because of infertility risk and those women with significant pelvic adhesions must be excluded. ${ }^{21,22}$ Yet again, fistulizing CD would likely be a relative contraindication to this technique due to the concern of developing an enterovaginal fistula.

\section{Enhanced Recovery Pathways}

Although MIS has offered a significant advancement over traditional open surgery in the treatment of patients with IBD, more benefits have been realized with the addition of an enhanced recovery protocol to perioperative care. Enhanced recovery after surgery (ERAS) encompasses a preoperative, intraoperative, and postoperative care regimen to improve patient outcomes. ${ }^{117}$ Preoperative education, fluid and 
carbohydrate loading, limiting the use of bowel preparations, and administration of antibiotic and thromboembolic prophylaxis encompass the primary preoperative goals of care. Intraoperative guidelines include utilization of short-acting anesthetic agents, midthoracic epidural, narcotic-sparing analgesics, avoidance of salt and water overload, and maintenance of normothermia. Postoperative management within an ERAS pathway includes immediate resumption of diet, stimulation of gut motility, prevention of nausea and vomiting, avoidance of salt and water overload, use of nonopioid oral analgesia, and early removal of urinary catheters and drains.

Several studies have demonstrated the benefits of an ERAS pathway in colon and rectal surgery when compared with traditional perioperative care. Shorter length of stay (e.g., as short as 2 days after TPC), ${ }^{118}$ decreased morbidity and mortality, and no increase in readmissions have been demonstrated in 2 systematic reviews: Spanjersberg et al (Cochrane, 2011) and Varadhan et al. ${ }^{19,120}$ Other studies have even demonstrated the benefits of ERAS combined with MIS in colon and rectal surgery over MIS techniques alone. ${ }^{121-125}$ Recently, Spinelli et al ${ }^{126}$ published the benefits of ERAS in patients with $\mathrm{CD}$ undergoing laparoscopic ileocolic resections demonstrating earlier return of bowel function and shorter length of stays. Overall, coupling an ERAS pathway to MIS maximizes the minimalist approach, while providing additional benefit over MIS alone and producing superior patient outcomes. Undoubtedly patients with IBD, after either open or laparoscopic surgery, will benefit from this ERAS approach, which mirrors and compliments MIS with the main goal of reducing the magnitude of perioperative physiologic stress and maintain homeostasis.

\section{CONCLUSIONS}

MIS for IBD is becoming the standard worldwide because of superior short- and long-term outcomes when performed by experienced surgeons. Although MIS for IBD has been extensively studied in an uncontrolled fashion, randomized trials are unlikely to occur as MIS approaches to colon and rectal surgery are quickly becoming the surgical approach of choice after level 1 evidence in other disease processes of the colon and rectum. Despite superiority of MIS for IBD in short-term perioperative outcomes and equivalence in many long-term outcomes, the steep learning curve, complex surgeries, and challenging anatomy continue to be barriers to the widespread application of MIS techniques for IBD. The advanced laparoscopic skills required and the potential difficult anatomic and operative conditions argue that these procedures should be performed at a tertiary referral center with a specialized surgeon. General and colorectal surgeons must remain fully engaged in the development and application of new technologies and innovative approaches to procedures so that surgeons can lead the way into the future while maintaining the patient's interests first. The increased use of innovative techniques should advance cautiously with proven patient benefit without increased morbidity.

\section{REFERENCES}

1. Bardakcioglu O, Khan A, Aldridge C, et al. Growth of laparoscopic colectomy in the United States: analysis of regional and socioeconomic factors over time. Ann Surg. 2013;258:270-274.

2. Vennix S, Pelzers L, Bouvy N, et al. Laparoscopic versus open total mesorectal excision for rectal cancer. Cochrane Database Syst Rev. 2014;4:CD005200.

3. Veldkamp R, Kuhry E, Hop WC, et al. Laparoscopic surgery versus open surgery for colon cancer: short-term outcomes of a randomised trial. Lancet Oncol. 2005;6:477-484.

4. Bjoholt I, Janson M, Jonsson B, et al. Principles for the design of the economic evaluation of COLOR II: an international clinical trial in surgery comparing laparoscopic and open surgery in rectal cancer. Int $J$ Technol Assess Health Care. 2006;22:130-135.

5. Color IISG, Buunen M, Bonjer HJ, et al. COLOR II. A randomized clinical trial comparing laparoscopic and open surgery for rectal cancer. Dan Med Bull. 2009;56:89-91.

6. Laurent $\mathrm{C}$, Leblanc F, Wutrich $\mathrm{P}$, et al. Laparoscopic versus open surgery for rectal cancer: long-term oncologic results. Ann Surg. 2009;250: 54-61.

7. Leung KL, Kwok SP, Lam SC, et al. Laparoscopic resection of rectosigmoid carcinoma: prospective randomised trial. Lancet. 2004;363: $1187-1192$.

8. Ng SS, Leung KL, Lee JF, et al. Long-term morbidity and oncologic outcomes of laparoscopic-assisted anterior resection for upper rectal cancer: ten-year results of a prospective, randomized trial. Dis Colon Rectum. 2009;52:558-566.

9. Ng SS, Leung KL, Lee JF, et al. Laparoscopic-assisted versus open abdominoperineal resection for low rectal cancer: a prospective randomized trial. Ann Surg Oncol. 2008;15:2418-2425.

10. Clinical Outcomes of Surgical Therapy Study Group. A comparison of laparoscopically assisted and open colectomy for colon cancer. $N$ Engl $J$ Med. 2004;350:2050-2059.

11. Braga M, Frasson M, Vignali A, et al. Laparoscopic vs. open colectomy in cancer patients: long-term complications, quality of life, and survival. Dis Colon Rectum. 2005;48:2217-2223.

12. Braga M, Vignali A, Gianotti L, et al. Laparoscopic versus open colorectal surgery: a randomized trial on short-term outcome. Ann Surg. 2002;236:759-766; disscussion 767.

13. Lacy AM, Delgado S, Castells A, et al. The long-term results of a randomized clinical trial of laparoscopy-assisted versus open surgery for colon cancer. Ann Surg. 2008;248:1-7.

14. Lacy AM, Garcia-Valdecasas JC, Delgado S, et al. Laparoscopy-assisted colectomy versus open colectomy for treatment of non-metastatic colon cancer: a randomised trial. Lancet. 2002;359:2224-2229.

15. Moftah M, Nazour F, Cunningham M, et al. Single port laparoscopic surgery for patients with complex and recurrent Crohn's disease. J Crohns Colitis. 2014;8:1055-1061.

16. Edden Y, Ciardullo J, Sherafgan K, et al. Laparoscopic-assisted ileocolic resection for Crohn's disease. JSLS. 2008;12:139-142.

17. Goyer P, Alves A, Bretagnol F, et al. Impact of complex Crohn's disease on the outcome of laparoscopic ileocecal resection: a comparative clinical study in 124 patients. Dis Colon Rectum. 2009;52:205-210.

18. Holubar SD, Wolff BG. Advances in surgical approaches to Crohn's disease: minimally invasive surgery and biologic therapy. Expert Rev Clin Immunol. 2009;5:463-470.

19. Holubar SD, Dozois EJ, Privitera A, et al. Laparoscopic surgery for recurrent ileocolic Crohn's disease. Inflamm Bowel Dis. 2010;16:1382-1386.

20. Seymour NE, Kavic SM. Laparoscopic management of complex Crohn's disease. JSLS. 2003;7:117-121.

21. Dozois EJ, Larson DW, Dowdy SC, et al. Transvaginal colonic extraction following combined hysterectomy and laparoscopic total colectomy: a natural orifice approach. Tech Coloproctol. 2008;12:251-254.

22. Park JS, Choi GS, Lim KH, et al. Clinical outcome of laparoscopic right hemicolectomy with transvaginal resection, anastomosis, and retrieval of specimen. Dis Colon Rectum. 2010;53:1473-1479.

23. Bernell O, Lapidus A, Hellers G. Risk factors for surgery and recurrence in 907 patients with primary ileocaecal Crohn's disease. Br J Surg. 2000; 87:1697-1701.

24. Bernell O, Lapidus A, Hellers G. Risk factors for surgery and postoperative recurrence in Crohn's disease. Ann Surg. 2000;231:38-45. 
25. Heimann TM, Greenstein AJ, Lewis B, et al. Comparison of primary and reoperative surgery in patients with Crohns disease. Ann Surg. 1998;227: 492-495.

26. Lesperance K, Martin MJ, Lehmann R, et al. National trends and outcomes for the surgical therapy of ileocolonic Crohn's disease: a population-based analysis of laparoscopic vs. open approaches. J Gastrointest Surg. 2009; 13:1251-1259.

27. Dasari BV, McKay D, Gardiner K. Laparoscopic versus Open surgery for small bowel Crohn's disease. Cochrane Database Syst Rev. 2011; CD006956.

28. Bauer JJ, Harris MT, Grumbach NM, et al. Laparoscopic-assisted intestinal resection for Crohn's disease. Dis Colon Rectum. 1995;38:712-715.

29. Alabaz O, Iroatulam AJ, Nessim A, et al. Comparison of laparoscopically assisted and conventional ileocolic resection for Crohn's disease. Eur J Surg. 2000;166:213--217.

30. Young-Fadok TM, HallLong K, McConnell EJ, et al. Advantages of laparoscopic resection for ileocolic Crohn's disease. Improved Outcomes and Reduced Costs. Surg Endosc. 2001;15:450-454.

31. Keller DS, Katz J, Stein SL, et al. Surgical cost of care in Crohn's disease. Pol Przegl Chir. 2013;85:511-516.

32. Maartense S, Dunker MS, Slors JF, et al. Laparoscopic-assisted versus open ileocolic resection for Crohn's disease: a randomized trial. Ann Surg. 2006;243:143-149; discussion 150-153.

33. Bergamaschi R, Pessaux P, Arnaud JP. Comparison of conventional and laparoscopic ileocolic resection for Crohn's disease. Dis Colon Rectum. 2003;46:1129-1133.

34. Milsom JW, Hammerhofer KA, Bohm B, et al. Prospective, randomized trial comparing laparoscopic vs. conventional surgery for refractory ileocolic Crohn's disease. Dis Colon Rectum. 2001;44:1-8; discussion 8-9.

35. Patel SV, Patel SV, Ramagopalan SV, et al. Laparoscopic surgery for Crohn's disease: a meta-analysis of perioperative complications and long term outcomes compared with open surgery. BMC Surg. 2013;13:14.

36. Rosman AS, Melis M, Fichera A. Metaanalysis of trials comparing laparoscopic and open surgery for Crohn's disease. Surg Endosc. 2005; $19: 1549-1555$.

37. Tan JJ, Tjandra JJ. Laparoscopic surgery for Crohn's disease: a metaanalysis. Dis Colon Rectum. 2007;50:576-585.

38. Tilney HS, Constantinides VA, Heriot AG, et al. Comparison of laparoscopic and open ileocecal resection for Crohn's disease: a metaanalysis. Surg Endosc. 2006;20:1036-1044.

39. Canin-Endres J, Salky B, Gattorno F, et al. Laparoscopically assisted intestinal resection in 88 patients with Crohn's disease. Surg Endosc. 1999; 13:595-599.

40. Soop M, Larson DW, Malireddy K, et al. Safety, feasibility, and shortterm outcomes of laparoscopically assisted primary ileocolic resection for Crohn's disease. Surg Endosc. 2009;23:1876-1881.

41. Beyer-Berjot L, Mancini J, Bege T, et al. Laparoscopic approach is feasible in Crohn's complex enterovisceral fistulas: a case-match review. Dis Colon Rectum. 2013;56:191-197.

42. Bellolio F, Cohen Z, Macrae HM, et al. Outcomes following surgery for perforating Crohn's disease. Br J Surg. 2013;100:1344-1348.

43. Alves A, Panis Y, Bouhnik Y, et al. Factors that predict conversion in 69 consecutive patients undergoing laparoscopic ileocecal resection for Crohn's disease: a prospective study. Dis Colon Rectum. 2005;48:2302-2308.

44. Wu JS, Birnbaum EH, Kodner IJ, et al. Laparoscopic-assisted ileocolic resections in patients with Crohn's disease: are abscesses, phlegmons, or recurrent disease contraindications? Surgery. 1997;122:682-688; discussion 688-689.

45. Pinto RA, Shawki S, Narita K, et al. Laparoscopy for recurrent Crohn's disease: how do the results compare with the results for primary Crohn's disease? Colorectal Dis. 2011;13:302-307.

46. Aytac E, Stocchi L, Remzi FH, et al. Is laparoscopic surgery for recurrent Crohn's disease beneficial in patients with previous primary resection through midline laparotomy? A case-matched study. Surg Endosc. 2012; 26:3552-3556.

47. Holubar SD, Dozois EJ, Privitera A, et al. Minimally invasive colectomy for Crohn's colitis: a single institution experience. Inflamm Bowel Dis. 2010;16:1940-1946.

48. Umanskiy K, Malhotra G, Chase A, et al. Laparoscopic colectomy for Crohn's colitis. A large prospective comparative study. J Gastrointest Surg. 2010;14:658-663.
49. da Luz Moreira A, Stocchi L, Remzi FH, et al. Laparoscopic surgery for patients with Crohn's colitis: a case-matched study. J Gastrointest Surg. 2007;11:1529-1533.

50. Kappelman MD, Rifas-Shiman SL, Porter CQ, et al. Direct health care costs of Crohn's disease and ulcerative colitis in US children and adults. Gastroenterology. 2008;135:1907-1913.

51. Loftus CG, Loftus EV, Jr., Harmsen WS, et al. Update on the incidence and prevalence of Crohn's disease and ulcerative colitis in Olmsted County, Minnesota, 1940-2000. Inflamm Bowel Dis. 2007; $13: 254-261$

52. Bach SP, Mortensen NJ. Revolution and evolution: 30 years of ileoanal pouch surgery. Inflamm Bowel Dis. 2006;12:131-145.

53. Hahnloser D, Pemberton JH, Wolff BG, et al. Results at up to 20 years after ileal pouch-anal anastomosis for chronic ulcerative colitis. $\mathrm{Br} \mathrm{J}$ Surg. 2007;94:333-340.

54. Ross H, Steele SR, Varma M, et al. Practice parameters for the surgical treatment of ulcerative colitis. Dis Colon Rectum. 2014;57:5-22.

55. Holubar SD, Privitera A, Cima RR, et al. Minimally invasive total proctocolectomy with Brooke ileostomy for ulcerative colitis. Inflamm Bowel Dis. 2009;15:1337-1342.

56. Peters WR. Laparoscopic total proctocolectomy with creation of ileostomy for ulcerative colitis: report of two cases. J Laparoendosc Surg. 1992;2:175-178.

57. Gorfine SR, Fichera A, Harris MT, et al. Long-term results of salvage surgery for septic complications after restorative proctocolectomy: does fecal diversion improve outcome? Dis Colon Rectum. 2003;46:1339-1344.

58. Holubar SD, Larson DW, Dozois EJ, et al. Minimally invasive subtotal colectomy and ileal pouch-anal anastomosis for fulminant ulcerative colitis: a reasonable approach? Dis Colon Rectum. 2009;52:187-192.

59. Swenson BR, Hollenbeak CS, Poritz LS, et al. Modified two-stage ileal pouch-anal anastomosis: equivalent outcomes with less resource utilization. Dis Colon Rectum. 2005;48:256-261.

60. Alves A, Panis Y, Bouhnik Y, et al. Subtotal colectomy for severe acute colitis: a 20-year experience of a tertiary care center with an aggressive and early surgical policy. J Am Coll Surg. 2003;197:379-385.

61. Hyman NH, Cataldo P, Osler T. Urgent subtotal colectomy for severe inflammatory bowel disease. Dis Colon Rectum. 2005;48:70-73.

62. Penna C, Daude F, Parc R, et al. Previous subtotal colectomy with ileostomy and sigmoidostomy improves the morbidity and early functional results after ileal pouch-anal anastomosis in ulcerative colitis. Dis Colon Rectum. 1993;36:343-348.

63. Teeuwen PH, Stommel MW, Bremers AJ, et al. Colectomy in patients with acute colitis: a systematic review. J Gastrointest Surg. 2009;13: 676-686.

64. Chung TP, Fleshman JW, Birnbaum EH, et al. Laparoscopic vs. open total abdominal colectomy for severe colitis: impact on recovery and subsequent completion restorative proctectomy. Dis Colon Rectum. 2009;52:4-10.

65. Dunker MS, Bemelman WA, Slors JF, et al. Laparoscopic-assisted vs open colectomy for severe acute colitis in patients with inflammatory bowel disease (IBD): a retrospective study in 42 patients. Surg Endosc. 2000;14:911-914.

66. Marceau C, Alves A, Ouaissi M, et al. Laparoscopic subtotal colectomy for acute or severe colitis complicating inflammatory bowel disease: a case-matched study in 88 patients. Surgery. 2007;141:640-644.

67. Marcello PW, Milsom JW, Wong SK, et al. Laparoscopic total colectomy for acute colitis: a case-control study. Dis Colon Rectum. 2001;44: 1441-1445.

68. Seshadri PA, Poulin EC, Schlachta CM, et al. Does a laparoscopic approach to total abdominal colectomy and proctocolectomy offer advantages? Surg Endosc. 2001;15:837-842.

69. Telem DA, Vine AJ, Swain G, et al. Laparoscopic subtotal colectomy for medically refractory ulcerative colitis: the time has come. Surg Endosc. 2010;24:1616-1620.

70. Bell RL, Seymour NE. Laparoscopic treatment of fulminant ulcerative colitis. Surg Endosc. 2002;16:1778-1782.

71. Proctor ML, Langer JC, Gerstle JT, et al. Is laparoscopic subtotal colectomy better than open subtotal colectomy in children? J Pediatr Surg. 2002;37:706-708.

72. Boushey RP, Marcello PW, Martel G, et al. Laparoscopic total colectomy: an evolutionary experience. Dis Colon Rectum. 2007;50:1512-1519.

1456 | www.ibdjournal.org 
73. Nakajima K, Lee SW, Cocilovo C, et al. Laparoscopic total colectomy: hand-assisted vs standard technique. Surg Endosc. 2004;18:582-586.

74. Pandey S, Luther G, Umanskiy K, et al. Minimally invasive pouch surgery for ulcerative colitis: is there a benefit in staging? Dis Colon Rectum. 2011;54:306-310.

75. Marcello PW, Milsom JW, Wong SK, et al. Laparoscopic restorative proctocolectomy: case-matched comparative study with open restorative proctocolectomy. Dis Colon Rectum. 2000;43:604-608.

76. Larson DW, Cima RR, Dozois EJ, et al. Safety, feasibility, and shortterm outcomes of laparoscopic ileal-pouch-anal anastomosis: a single institutional case-matched experience. Ann Surg. 2006;243:667-670; discussion 670-672.

77. Linden BC, Bairdain S, Zurakowski D, et al. Comparison of laparoscopicassisted and open total proctocolectomy and ileal pouch anal anastomosis in children and adolescents. J Pediatr Surg. 2013;48:1546-1550.

78. Tan JJ, Tjandra JJ. Laparoscopic surgery for ulcerative colitis-a metaanalysis. Colorectal Dis. 2006;8:626-636.

79. Wu XJ, He XS, Zhou XY, et al. The role of laparoscopic surgery for ulcerative colitis: systematic review with meta-analysis. Int $J$ Colorectal Dis. 2010;25:949-957.

80. Ahmed Ali U, Keus F, Heikens JT, et al. Open versus laparoscopic (assisted) ileo pouch anal anastomosis for ulcerative colitis and familial adenomatous polyposis. Cochrane Database Syst Rev. 2009;CD006267.

81. Fleming FJ, Francone TD, Kim MJ, et al. A laparoscopic approach does reduce short-term complications in patients undergoing ileal pouch-anal anastomosis. Dis Colon Rectum. 2011;54:176-182.

82. Selvasekar CR, Cima RR, Larson DW, et al. Effect of infliximab on shortterm complications in patients undergoing operation for chronic ulcerative colitis. J Am Coll Surg. 2007;204:956-962; discussion 962-963.

83. Hicks CW, Hodin RA, Bordeianou L. Possible overuse of 3-stage procedures for active ulcerative colitis. JAMA Surg. 2013;148:658-664.

84. Polle SW, Dunker MS, Slors JF, et al. Body image, cosmesis, quality of life, and functional outcome of hand-assisted laparoscopic versus open restorative proctocolectomy: long-term results of a randomized trial. Surg Endosc. 2007;21:1301-1307.

85. Dunker MS, Bemelman WA, Slors JF, et al. Functional outcome, quality of life, body image, and cosmesis in patients after laparoscopic-assisted and conventional restorative proctocolectomy: a comparative study. Dis Colon Rectum. 2001;44:1800-1807.

86. Fichera A, Silvestri MT, Hurst RD, et al. Laparoscopic restorative proctocolectomy with ileal pouch anal anastomosis: a comparative observational study on long-term functional results. J Gastrointest Surg. 2009;13:526-532.

87. Ky AJ, Sonoda T, Milsom JW. One-stage laparoscopic restorative proctocolectomy: an alternative to the conventional approach? Dis Colon Rectum. 2002;45:207-210; discussion 210-211.

88. Gorfine SR, Gelernt IM, Bauer JJ, et al. Restorative proctocolectomy without diverting ileostomy. Dis Colon Rectum. 1995;38:188-194.

89. Kiely JM, Fazio VW, Remzi FH, et al. Pelvic sepsis after IPAA adversely affects function of the pouch and quality of life. Dis Colon Rectum. 2012;55:387-392.

90. Selvaggi F, Sciaudone G, Limongelli P, et al. The effect of pelvic septic complications on function and quality of life after ileal pouch-anal anastomosis: a single center experience. Am Surg. 2010;76:428-435.

91. Holder-Murray J, Zoccali M, Hurst RD, et al. Totally laparoscopic total proctocolectomy: a safe alternative to open surgery in inflammatory bowel disease. Inflamm Bowel Dis. 2012;18:863-868

92. Holubar SD. Laparoscopic total colectomy with brooke ileostomy for chronic ulcerative colitis after orthotopic liver transplantation for primary sclerosing cholangitis. Dis Colon Rectum. 2014;57:800.

93. Rijcken E, Mennigen R, Argyris I, et al. Single-incision laparoscopic surgery for ileocolic resection in Crohn's disease. Dis Colon Rectum. 2012;55:140-146.

94. Fichera A, Zoccali M, Felice C, et al. Total abdominal colectomy for refractory ulcerative colitis. Surgical treatment in evolution. $J$ Gastrointest Surg. 2011;15:1909-1916.

95. Gash KJ, Goede AC, Kaldowski B, et al. Single incision laparoscopic (SILS) restorative proctocolectomy with ileal pouch-anal anastomosis. Surg Endosc. 2011;25:3877-3880.

96. Maggiori L, Gaujoux S, Tribillon E, et al. Single-incision laparoscopy for colorectal resection: a systematic review and meta-analysis of more than a thousand procedures. Colorectal Dis. 2012;14:e643-e654.
97. Fung AK, Aly EH. Systematic review of single-incision laparoscopic colonic surgery. Br J Surg. 2012;99:1353-1364.

98. Li P, Wang DR, Wang LH, et al. Single-incision laparoscopic surgery vs. multiport laparoscopic surgery for colectomy: a meta-analysis of eleven recent studies. Hepatogastroenterology. 2012;59:1345-1349.

99. Vettoretto N, Cirocchi R, Randolph J, et al. Single incision laparoscopic right colectomy: a systematic review and meta-analysis. Colorectal Dis. 2014;16:0123-O132.

100. Yang TX, Chua TC. Single-incision laparoscopic colectomy versus conventional multiport laparoscopic colectomy: a meta-analysis of comparative studies. Int J Colorectal Dis. 2013;28:89-101.

101. Baik SH, Kwon HY, Kim JS, et al. Robotic versus laparoscopic low anterior resection of rectal cancer: short-term outcome of a prospective comparative study. Ann Surg Oncol. 2009;16:1480-1487.

102. Baek JH, Pastor C, Pigazzi A. Robotic and laparoscopic total mesorectal excision for rectal cancer: a case-matched study. Surg Endosc. 2011;25: 521-525.

103. Bianchi PP, Ceriani C, Locatelli A, et al. Robotic versus laparoscopic total mesorectal excision for rectal cancer: a comparative analysis of oncological safety and short-term outcomes. Surg Endosc. 2010;24: 2888-2894.

104. Park JS, Choi GS, Lim KH, et al. Robotic-assisted versus laparoscopic surgery for low rectal cancer: case-matched analysis of short-term outcomes. Ann Surg Oncol. 2010;17:3195-3202.

105. McLemore EC, Cullen J, Horgan S, et al. Robotic-assisted laparoscopic stage II restorative proctectomy for toxic ulcerative colitis. Int $\mathrm{J}$ Med Robot. 2012;8:178-183.

106. Miller AT, Berian JR, Rubin M, et al. Robotic-assisted proctectomy for inflammatory bowel disease: a case-matched comparison of laparoscopic and robotic technique. J Gastrointest Surg. 2012;16:587-594.

107. Pedraza R, Patel CB, Ramos-Valadez DI, et al. Robotic-assisted laparoscopic surgery for restorative proctocolectomy with ileal J pouch-anal anastomosis. Minim Invasive Ther Allied Technol. 2011;20:234-239.

108. Buchs NC, Pugin F, Bucher P, et al. Totally robotic right colectomy: a preliminary case series and an overview of the literature. Int $\mathrm{J}$ Med Robot. 2011;7:348-352.

109. D’Annibale A, Pernazza G, Morpurgo E, et al. Robotic right colon resection: evaluation of first 50 consecutive cases for malignant disease. Ann Surg Oncol. 2010;17:2856-2862.

110. Park SY, Choi GS, Park JS, et al. Robot-assisted right colectomy with lymphadenectomy and intracorporeal anastomosis for colon cancer: technical considerations. Surg Laparosc Endosc Percutan Tech. 2012;22: e271-e276.

111. Trastulli S, Desiderio J, Farinacci F, et al. Robotic right colectomy for cancer with intracorporeal anastomosis: short-term outcomes from a single institution. Int $J$ Colorectal Dis. 2013;28:807-814.

112. Park JS, Choi GS, Park SY, et al. Randomized clinical trial of robotassisted versus standard laparoscopic right colectomy. Br J Surg. 2012; 99:1219-1226.

113. Kim CW, Kim CH, Baik SH. Outcomes of robotic-assisted colorectal surgery compared with laparoscopic and open surgery: a systematic review. J Gastrointest Surg. 2014;18:816-830.

114. Juo YY, Obias V. Robot-assisted single-incision total colectomy: a case report. Int J Med Robot. [published online ahead of print May 28, 2014]. doi: $10.1002 /$ rcs. 1593 .

115. Ostrowitz MB, Eschete D, Zemon H, et al. Robotic-assisted singleincision right colectomy: early experience. Int $J$ Med Robot. 2009;5: $465-470$.

116. Whiteford MH, Denk PM, Swanstrom LL. Feasibility of radical sigmoid colectomy performed as natural orifice translumenal endoscopic surgery (NOTES) using transanal endoscopic microsurgery. Surg Endosc. 2007; 21:1870-1874.

117. Gustafsson UO, Scott MJ, Schwenk W, et al. Guidelines for perioperative care in elective colonic surgery: enhanced recovery after surgery (ERAS) society recommendations. World J Surg. 2013;37:259-284.

118. Lovely JK, Maxson PM, Jacob AK, et al. Case-matched series of enhanced versus standard recovery pathway in minimally invasive colorectal surgery. Br J Surg. 2012;99:120-126.

119. Spanjersberg WR, Reurings J, Keus F, et al. Fast track surgery versus conventional recovery strategies for colorectal surgery. Cochrane Database Syst Rev. 2011;CD007635. 
120. Varadhan KK, Neal KR, Dejong CH, et al. The enhanced recovery after surgery (ERAS) pathway for patients undergoing major elective open colorectal surgery: a meta-analysis of randomized controlled trials. Clin Nutr. 2010;29:434-440.

121. Esteban F, Cerdan FJ, Garcia-Alonso M, et al. A multicentre comparison of a fast track or conventional postoperative protocol following laparoscopic or open elective surgery for colorectal cancer surgery. Colorectal Dis. 2014;16:134-140.

122. Feroci F, Kroning KC, Lenzi E, et al. Laparoscopy within a fast-track program enhances the short-term results after elective surgery for resectable colorectal cancer. Surg Endosc. 2011;25:2919-2925.
123. Haverkamp MP, de Roos MA, Ong KH. The ERAS protocol reduces the length of stay after laparoscopic colectomies. Surg Endosc. 2012;26:361-367.

124. Kolozsvari NO, Capretti G, Kaneva P, et al. Impact of an enhanced recovery program on short-term outcomes after scheduled laparoscopic colon resection. Surg Endosc. 2013;27:133-138.

125. Poon JT, Fan JK, Lo OS, et al. Enhanced recovery program in laparoscopic colectomy for cancer. Int J Colorectal Dis. 2011;26:71-77.

126. Spinelli A, Bazzi P, Sacchi M, et al. Short-term outcomes of laparoscopy combined with enhanced recovery pathway after ileocecal resection for Crohn's disease: a case-matched analysis. J Gastrointest Surg. 2013;17: 126-132; discussion 132 . 